2010

\title{
Producing an Insightful Research Paper: Some Elements to Consider
}

Craig Scott

Osgoode Hall Law School of York University

Follow this and additional works at: http://digitalcommons.osgoode.yorku.ca/all_papers

\section{Repository Citation}

Scott, Craig, "Producing an Insightful Research Paper: Some Elements to Consider" (2010). All Papers. Paper 26.

http://digitalcommons.osgoode.yorku.ca/all_papers/26

This Working Paper is brought to you for free and open access by the Research Papers, Working Papers, Conference Papers at Osgoode Digital

Commons. It has been accepted for inclusion in All Papers by an authorized administrator of Osgoode Digital Commons. 


\title{
PRODUCING AN INSIGHTFUL RESEARCH PAPER: SOME ELEMENTS TO CONSIDER
}

\author{
Craig Scott ${ }^{*}$
}

This paper originated as a lecture to students pursuing the Erasmus Mundus Master of Laws in Transnational Trade and Finance Law at the Universidad de Deusto, Bilbao, Spain. Although generally relevant for researchers in a variety of contexts up to and including writing book monographs, it is primarily aimed at graduate students doing major papers, theses or dissertations and undergraduate (including first-degree law) students doing research essays in upper-year seminars. The pointers found in the paper must accordingly be modified, mutatis mutandi, according to the nature of the research project, including the time available in which to complete it. The paper is divided into four sections: "Principles" (section I); "The notion of 'insight" (Section II); "Presumptive research steps" (Section III); "Tips" (Section IV); and "Conclusion" (Section V).

\section{Principles}

As with all principles, there may be tensions amongst these. Indeed, some of the following principles are themselves expressed in terms of balancing or in terms of contrasting pairs.

1. Use your supervisor's time effectively.

2. You are primarily responsible for your paper. Your supervisor's role is subsidiary.

3. Form good habits early. This leads to consistency of effective research and writing methods that become second nature with time.

4. In planning an essay and then in writing it, seek a balance between structure and flow (although never sacrifice flow: sequitur, sequitur, sequitur should be your motto).

5. In research, seek a balance between selectivity (i.e. of what you read quite closely) and comprehensiveness. The precise balance will depend on the kind of essay (a seminar paper, a major paper, a thesis, an article, etc.).

6. Take time to familiarize yourself with relevant research tools for your area (library, databases, relevant Internet sites).

7. In writing, seek a balance between exposition (description, scene-setting, etc) and reflection (analysis, synthesis, critique, etc).

\footnotetext{
* Professor of Law, Osgoode Hall Law School of York University, Toronto.
} 
8. In writing, seek a balance between general argumentation and employment of concrete illustrations/examples.

9. In writing, both clarity and elegance of expression matter. Good writing engages readers and helps make your arguments more persuasive.

10. In writing, developing an argument through others' research and ideas is important (which must always be properly attributed), but so too is developing your own arguments in your own voice.

11. In writing, rigour in argument is essential. Simply asserting points as "self-evident" or "logical" does not amount to rigorous argument. (See, below, tips on the importance of premises to sound argument.)

12. Think of "insight" as your beacon (the light in the distance that you are traveling towards).

13. We are all hypocrites and don't always do what we say, but that can make what we say all the more valuable by virtue of how much we regret what we do. This applies to professors giving young scholars research advice as it does to much of life.

\section{The notion of "insight"}

As indicated by the penultimate principle in the preceding section, I find "insight" to be a better expression of the primary objective for an excellent essay than "originality," although the two concepts are close. "Originality" sets expectations too high and can cause paralysis for young scholars because it seems so demanding. More importantly, speaking of "originality" can over-emphasize newness for its own sake and under-emphasize how important it is to build on the knowledge that comes before us.

What do I mean by "insight"? To put it as simply as possible, think of it as a helpful or interesting way of looking at an issue or problem.

That said, for higher levels of essay work (like dissertations, scholarly articles and so on), the goal should also be to have a measure of originality as part of your insights. But, importantly, do not think of originality in terms of newness (i.e. something that has never been noted or perceived or said before) but instead in terms of added value. Even if others have made the same point before, they may have not come to the same point with the same mix of arguments and the same ways of expressing the matter. If your mix of arguments (whether as analysis or as synthesis) and your ways of expressing your arguments result in some readers understanding the issue or problem better than before, then, from my perspective, this adds value to existing knowledge and thus counts as original.

To help underline the above points in a way that should put you on course to be future Nobel Prize laureates in Law (should such a prize ever be added to the current Nobel Prizes), consider the following quotation from the 18 October 2008 issue of The Economist 
magazine (at page 85) with respect to the justification for the award to Paul Krugman of the Nobel Prize in Economics:

In neither [Nobel Prize Committee-cited] contribution [one on international trade and one on economic geography] did Mr Krugman claim great originality for his ideas ...His achievement was to formalize insights that many people had previously had informally. Ideas that had fluttered in and put of people's grasp for decades, he pinned down like a butterfly on display. Sometimes a good economist...succeeds not by making a point before someone everyone else, but by making it better than anyone else.

\section{Presumptive Research Steps}

I use the word "presumptive" because it is important to recognize that we all end up working a bit differently. Sometimes some of us can be very effective by skipping stages that others cannot skip or by changing the order of stages or by breaking a stage up into segments that we mix in with other stages. But, as a starting point, keep the following steps in mind:

A. Decide on the essay concept and write a mini-proposal to yourself (which can also then be used for your supervisor to give feedback on the topic) - What is your topic? What is the basic question (or several questions) that will animate your research on that topic? Try to write your essay concept down in less than 250 words (and revise the description as your thinking progresses).

B. Bibliographic research - In light of the concept, (a) familiarize yourself with the relevant sources and then (b) do an initial 'long list' bibliography of existing literature (including primary documents - legislation, treaties, case law, etc) that initially appear relevant.

C. Bibliographic sorting - Then, without yet having looked at anything beyond titles, do a preliminary sorting of the long list into three categories: 1) those that appear (from the titles and, as you get to know your field, the authors) to almost certainly be very important; 2) those that seem likely to be of some importance (if you were to have time to consult them) but not as important as category 1 ; 3) and those that seem likely to be of marginal or no use.

D. "First-pass" reading for a second sorting of the bibliography - Set aside a number of hours over several days to engage in intelligent skimming (or, scan reading) of the works in the above three categories. (See the Tips section on scan reading.) Your goal is to come up with a refined bibliographic list that you will later read with more care (and take notes on); a sub-goal is to identify the truly essential readings, which are the ones you should read ahead of the others. For works in each category, decide whether to retain the works in that category or to move it to one of the other categories. For those that stay in or are moved to category 1 (see sub-section $\mathrm{C}$, above), you may wish to use an additional annotation system (like an asterisk - *) to identify the super-important works. One of the reasons that it is important to take some time initially to sort out the categories before 
starting to read closely is that it gives you a basis for making decisions later in your research about when it is okay to stop reading and start writing, if it appears you are getting pressed for time.

E. Revised description and first outline - Now that you have done some skim reading and produced a newly sorted bibliography, return to the your topic/concept description (step A) and decide whether it needs a little revising. Once that is done, create an outline of how you think the paper (based on your current general knowledge) should be structured. You can use a system to identify sections in the outline that may prove not to be important to include, or that you may need to exclude if time is tight towards the end of the writing stage (e.g. italicize or underline the sections that are ideal but perhaps not crucial). Think of the outline as the table of contents for your essay; use a numbering system (Part 1, Section A, sub-section (i), or some such system), because this will allow you to mark the relevant sections on the notes that you take while researching. It is up to you whether you wish to add short digests in some or all of the outline's sections as to the kind of questions you will address and what things you need to look for when you start reading more closely.

F. Close reading of category 1 works and note-taking - If you used an asterisk system to identify the super-important works, start with them and read as closely as necessary to understand the work and to spend extra time grasping the parts of the work most relevant for your own paper. By the time you finish the super-important works, you will likely have started to develop a level of confidence that allows you to read more selectively as you more easily find the parts of the work that are most important. That said, there will be works that you simply must read closely in their entirety; this is especially the case in closely-argued philosophical papers where nuances may be missed if you dip in and out of the work too much. As for note-taking, it is very personal. I still prefer using index cards and writing notes by hand, but this is probably a function of the habits I formed when a graduate student. There are lots of electronic index-card programs out there, which at minimum have the benefit of allowing you to copy relevant passages from an electronic version of an article that you may be reading and paste them into the index card. But, the point is that you have to develop your own comfort level with how you take notes, notably with respect to how much detail (which is partly a function of whether the work or a photocopy or an e-copy will remain closely at hand for you to consult later, in which case more spare notes are possible) and with respect to whether you create a new card for distinct points. It is also up to you whether to read with your outline close at hand and to use the numbering system from the outline to annotate your notes so that you are, already at this stage, identifying where these notes will likely prove of the most relevance when the time comes to sort the notes and get down to writing.

G. General consultation of notes and then revision of outline - Once you have finished your reading and associated note-taking, you should look at your first outline, then flip through your notes with that outline in mind, and then return to the outline in order to decide whether to revise it. When revising the outline, you should retain (e.g. in parentheses) the old numbers for a section if it gets renumbered - if you have already started putting outline section numbers on your notes - because you will need to return to your notes and revise the numbers. 
H. Write first draft - Here, I will not say much more as writing is a very personal thing. Look to the Principles and Tips sections for some considerations that may prove relevant to your writing (e.g. the suggestion to write a précis of a section before writing it in full or the advice to carefully inspect the transitions between sections to make sure you have both structure and flow).

I. Pause, go to a movie and poke some fun at your friends who are still writing their first draft - See the tip on waiting a little while, if you have time before your deadline, before you start to edit.

J. Hand-edit your first draft for substance as well as for style - As with writing, there is not much I will say. Good editing is a talent all to itself, but it is crucial to note that it is part of good writing. I have heard it said by a novelist that her novels are $20 \%$ first draft and $80 \%$ editing. While that is of course far too much for a basic university essay, it does give you the idea that editing should not be thought of as a luxury, least of all as something that can be done simply with a spell-check program on a computer. The reason I suggest hand-editing (the old-fashioned making of marks on paper with ink or graphite) is that I believe it concentrates the mind. It also results de facto in not one but two stages of editing: the first stage is the hand-edit and the second stage is when you enter the edits into the computer (at which stage you will almost certainly be finding yourself perfecting your own edits as you enter them).

K. Go to another movie if you have time and then read the paper one last time Make sure the writing (grammar, syntax, clarity, etc) is as good as you can expect. You may find yourself making one or two substantive changes as well, but the primary purpose is to produce a nice, clean final product that your supervisor will love you for.

L. Submit the final essay and go to another movie - Congratulations.

M. If this is a dissertation or an article or a book, expect sometime in the future to do at least a couple more rounds of further revisions - This will be as a result of feedback from your supervisor, examining committee, journal editor, book publisher, and so on. Look forward to another movie once it is finally done.

\section{Tips}

Note that the following tips are in a fairly random order:

- Develop your own skills and comfort level for scan reading. The only basic advice I will give is that I normally find it useful to skim in the following stages: 1) read the entire introduction quickly; 2) scan the headings and sub-headings of the entire work (in the case of most books and some journal articles, this can be done by looking at the table of contents); and 3) read the conclusion quickly. This is enough to reach a preliminary conclusion on the category of importance/relevance $(1,2$ or 3 - see Presumptive Research Steps above) in which to place the work you are reading. If it is 
not, then you will need to use your best judgment to do some additional speed reading in order to make that final determination.

- Accept that you sometimes have to stop reading even though you feel there is more (sometimes much more) that you should or could read. In order to leave yourself time to write and edit, you will almost always need to set artificial deadlines about when to stop reading.

- For your topic and associated essay concept, lean toward the narrow over the broad while at the same time treating the topic/concept proportionately to the seriousness of the essay. (A topic may be too narrow to permit a developed discussion for an entire dissertation. A topic that is good for a $\mathrm{PhD}$ is very unlikely to be advisable for an essay in an undergraduate seminar. And so on.)

- Brainstorm at major decision points (e.g. what topic and associated issues to research; what aspects to include or exclude; whether to rely on a particular line of argument; etc), ideally both with your supervisor and separately with student colleagues.

- Especially for shorter essays in time-limited contexts, learn the art of 'bracketing' issues and angles. Everyone has 20/20 vision in hindsight and we always find it easiest to criticize others' work by pointing out what they should have addressed. But every article cannot be a book, and every undergraduate essay cannot be a masters thesis or PhD dissertation. So, you should make sure to include brief but clear statements of what you are knowingly and deliberately excluding from the essay (this is what I call 'bracketing'); these can be in the introduction section or, occasionally as needed throughout your essay, in footnotes. It is a bit of an art in two respects. You first have to predict what others will think you should have addressed and you secondly need to phrase the exclusion without making it sound defensive (as if you are making an excuse for something you actually think you should have included). Obviously, for shorter essays in the context of university programs, it is sufficient to say that time and space does not permit coverage of the excluded elements. For scholarly articles and books, it takes more explaining to make it seem reasonable that something was sidestepped or 'bracketed.' One device is to point out how the bracketed issues are a logical future step to pursue but need not be addressed at this point for the essay to have value.

- In all writing, your ultimate aim is to convince an assumed audience (who will or may read your essay) of the merits of the essay (both the value of even spending time on the topic and the worth of the arguments you make). If that is true, think of persuasion as an overarching orientation to your own arguments when you are writing your essay. Would this convince someone reading my essay in a reflective and fair way? Do I need to make one or more premises/assumptions more explicit in order for them to follow my argument and do I need to deepen those premises/assumptions for the reader not only to follow but also to accept my argument? 
- The most persuasive essays tend to be those that both acknowledge counterperspectives and depict those counter-perspectives with reasonable fairness, before then going on to demonstrate why those counter-perspectives are mistaken (whether in whole or only in part). There are limits to how extensively one can do this for short essays in limited-time contexts, but it is still a useful ideal to seek to achieve as much as possible.

- Footnotes or endnotes: I am biased toward footnotes. I like to see what is important enough to be cited, and I hate having to flip to the back of a work in order to find the reference. Others feel differently, but I am right and they are wrong ....:) How's that for a persuasive argument?

- One approach to producing insights (in the sense described earlier) is to use the method of framing issues and problems in different ways from the ways they have been presented/described in the literature that comes before you. This is of course reframing in ways you consider helpful, not just reframing for its own sake; you want the new frame to make the painting look better not just the same as before.

- Explanation of what others have said or argued is a valuable part of scholarship. Explanation by descriptive distillation is very often necessary to set the ground for subsequent analysis and it can also produce insights because you may distill matters better than others have done. But, it is also dangerous to rely on explanation alone to be the point of an essay because it is still a form of description and also risks having the reader think you are really only repeating what others have said. So, you should strive for something that feels like an insightful synthesis in which you add value by observing both where prior arguments are compatible with each other (or even mutually supporting of each other) and where some arguments stand in tension with (or possibly complete opposition to) each other.

- Use section headings as markers for giving structure and providing guides as to the progression of the overall argument. But, do not over-use them (in the style of some academic traditions) to the point that distinction upon distinction is made and you end up not being able to 'see the forest for the trees.'

- Always check and refine transitions between sections as part of the final editing process; this ensures you have managed to create flow at the same time as structure.

- The conclusion to the essay is best used for either crystallizing the final or overall argument or briefly reminding the reader of the key point/s of the article. It should not be a reiteration, however condensed, of what you have already written nor, least of all, a detailed after-the-fact roadmap (so, not: "In this essay, I have done ' $x, y$ and $z$ ' in section 1, ' $a, b$, and c' in section 2, etc....'). As well, the ideal conclusion should be fairly brief because the key arguments should already have been made. Also, stylistically, a brief conclusion helps leave the impression with the reader of a clear and focused essay. 
- Do not write by over-citation, which can result in the citations submerging your own voice. Learn to précis and to attribute generally to a source, thus retaining your own way of expressing the matter.

- Beware of passages or points that will appear to the reader like they have been "parachuted" into the piece (i.e. no clear connection to what has come before or, worse, also no clear connection to what comes afterward).

- In arguing your points, know what your premises are and when to make them explicit so that the reader can more easily follow why you believe a specific conclusion follows from your arguments.

- Do not be lazy with your writing style. At least at the final editing stages, make sure you look for all grammatical errors including problems of syntax. If a reader keeps coming up against poor writing, it affects her impression of the substantive argument. Consider asking a friend (who has enough knowledge of law) to read the final version to catch any lingering problems; ask her to point out (a) clear grammatical mistakes and (b) sentences where she simply cannot follow what you intend to say.

- Less is often more. (This is a rule I break too often.) This refers both to the overall length of an essay and to the length of component parts (from individual sentences to sub-sections). It is fine to write at some length when just 'getting your basic argument down on paper' but then you should make sure you have left enough editing time to allow you to make your arguments as tight as possible. Although it is a bit simplistic to say what I am about to say, it is often true that forcing yourself to cut length by at least $10 \%$ (perhaps even $20 \%$ ) can result in the realization that you can make the same point more sharply and clearly - and thus more effectively.

- Be prepared to suggest a process for interacting with your supervisor that you feel will be of most benefit to you, but ultimately be prepared to adjust to your supervisor's way of working. The more flexible you are prepared to be, the more you will get out of the experience and the less frustration you will feel.

- Many scholars are not very organized and especially not very good at keeping track of things. Early in your career, you should try to develop good record-keeping and planning habits. One place to start is to make sure you keep good records of all of your interactions with your supervisor: emails, drafts provided (with dates), copies of any written notes from the supervisor (e.g. on your drafts), transcriptions of any oral feedback from the supervisor during an appointment, and so on. Because a paper evolves over a period of time (and some may span several years, like $\mathrm{PhD}$ dissertations), it is often the case that you will periodically need to brief (if not rebrief) the supervisor on where things stand - what you have discussed before, which version of a draft you are now discussing, and so on. You keep the records because most supervisors will not do it well. 
- Consider suggesting to your supervisor a little 'trick' that I use in my own supervisions. I suggest to my supervisees that "short chunk" meetings can be more useful than trying to get feedback on a long portion of work. These short-chunk meetings involve the student bringing a piece of writing to the meeting for the supervisor to read on the spot (while the student reads something else to pass the time). The supervisor then gives immediate feedback, which can include handing back the written work with annotations made while reading. Meetings need to be scheduled to be longer than usual to take into account how long it takes to read the agreed number of pages; for example, I will schedule 45 minutes to an hour for 15 double-spaced pages of writing, with 20-30 minutes for reading and 15-25 minutes for discussion. But the benefits of this approach include: (a) it avoids supervisor delays in reading longer drafts, however well in advance of a meeting you submit the long draft; (b) it generates feedback when the text is fresh in the mind of both student and supervisor; and (c) it produces a focused and usually very productive meeting.

- When submitting a new draft of something already read by the supervisor, it can be helpful if it is highlighted to show where you have reworked or added material. Supervisors only have so much time, and do not appreciate having to read $90 \%$ of the same material in order to actually find $10 \%$ of new material.

- Pause before re-reading your own work. Give it something like two days. It helps you detect undue looseness or even laziness in your formulations and arguments.

- Just as I have suggested supervisors have certain pathologies you need to take into account, be aware of your own pathologies and make efforts to counteract them. For example, if you have a tendency to procrastinate or a tendency to read too much or a tendency to read too closely or a tendency to do your writing when you are not fresh, then make conscious efforts not to do these things.

- For a short essay, even a single insight suffices. Some of the best published articles have a single value-added point, albeit well developed and well argued.

- Create your own rolling list of sources (catalogues, databases, relevant websites, printed bibliographies, leading journals, etc) for your area/s of research. They are "rolling" in that you modify and add to them as you gain experience in the field.

- Create your own order of work for your research. By "order of work", I mean the steps you take to start and finish a research essay. Although there are some suggested standard stages (see Presumptive Research Steps section, earlier), we each may have our own variations that we find useful. Not everyone likes to do all their research before starting to write, for example. Others like everything to be done before writing, albeit leaving some possibility for a little more research to be done if one comes up against an unexpected gap. The point of writing out your own order of work is to encourage you to think explicitly about work habits that make sense for you and to then develop a consistently effective way of researching. Habits tend to 
stick with you, and that includes sloppy or ineffective research habits. To develop effective research habits that stay with you, the earlier the better.

- You should consider building up your own personal "research guide" of everything you learn that has proven useful to you in your research, from sources to process. Notwithstanding what I say below about the dangers of relying on the Internet, you may wish to consider building your own personal research portal by making use of one of the free 'dashboards' out there that allows you to customize your own web interface (and use it as a home page, if you like) with links to all the relevant places on the web for your research, from university catalogue websites to scholarly discussion forums to splash pages for commercial legal-research databases. Google has a facility that you can use to build your own portal but there are others.

- Notwithstanding the foregoing point tip, beware of the Internet as a primary, let alone a sole, source for research, except as a medium to access professional research databases. Some websites have accurate and reliable information, but you should assume $99 \%$ of what you find on the Internet (especially through a simple Google search) is not something to rely on in a scholarly essay. Do not cite Wikipedia as a source, even if you may of course legitimately use it as a background source to get an initial idea about a topic. As a flipside of this principle, get to know (and love) the libraries you have access to. Spend some time wandering the sections relevant to your work and spend some time learning reference sources (bibliographies, indices, etc) that are still in print only.

- Be especially aware of how badly the library profession has catalogued chapters in edited books. Finding good work in edited books often requires discovering a title that seems very useful and then going to physically look at the book so you see what chapters are in it.

- Do not rely on articles simply because they tend, for the most part, to be more accessible via electronic databases. While, in some fields, articles will be the dominant form of scholarship, it will still be the case that there will be key books for your research topic.

- Writing outlines at different stages, starting as soon as you feel you have a basic sense of the issues you want to research, can be helpful. It is a focused way of constantly reflecting on your ideas, without having to do a lot of writing.

- Before you start writing the paper (or any given section of it), consider clarifying your arguments to yourself in précis (short) form before writing the actual section/s. Sketch before you paint. Like a good painter, you can always depart from the sketch as you paint, but you will almost always be glad to have taken the time to have a sketch to refer to.

- Especially in advanced scholarly contexts, it is almost always useful if colleagues with some degree of familiarity with your topic (or the area/s of law to which it relates) can read the penultimate draft and offer some comments. People are busy, but if 
you make sure that even one comment is welcome, you will increase the chances others will give it a look and give you some useful feedback.

- As part of starting to build your own personal research guide, write down all the tips that you think I missed. There are bound to be a number of them.

\section{Conclusion}

Take everything I have said with a grain of salt. Ultimately, the only truly key advice for producing insightful research papers is to develop early in one's writing career the habits that prove to be effective for your own style and for the particularities of your own research questions; the above considerations will hopefully assist in fashioning the best approach for you. The corollary advice is not to allow careless or inefficient research and writing habits to become so ingrained that they end up hard-wired and extremely difficult to modify down the road. 